\title{
Khazanah
}

\section{ROSCOE POUND}

Roscoe Pound adalah salah satu pemikir hukum dunia yang nama dan pemikirannya selalu diperbincangkan dan diperhitungkan. ${ }^{1}$ la adalah salah seorang pemuka aliran sociological jurisprudence dan pragmatic legal realism. ${ }^{2}$ Roscoe Pound juga dikenal sebagai figur yang memiliki kecenderungan kuat untuk membuat klasifikasi mengenai bahan-bahan hukum (legal material). Hal ini dapat dipahami karena latar belakangnya sebagai sarjana biologi, sehingga sebagian pakar menjuluki Pound sebagai figur yang telah melakukan botanisasi hukum (botanized law). ${ }^{3}$ Selain itu, Pound juga banyak menggunakan teori-teori pemikir hukum lainnya di antaranya dari Rudolf Von Jhering (1818 - 1892) khususnya terkait dengan fungsi hukum sebagai sarana untuk melindungi kepentingan. ${ }^{4}$ Sehubungan dengan hal ini, Lyoid mengatakan sebagai berikut: "According to Pound, law should realize and protect six social interests: common security, social institutions (like family, religion and political rights), sense of morality, social goods, economic, cultural and political progress and protection of an individual's life. The last of these 'social interests' Pound deems to be the most important. In order to realize those goals a new sociological jurisprudence, Pound argues, must be developed". 5

Pound membedakan antara sociological jurisprudence dengan sociology of law. Istilah pertama merujuk kepada hal-hal yang bersifat praktik (practical), yaitu terkait dengan bagaimana hukum itu dilaksanakan sedangkan istilah kedua berhubungan dengan masalah-masalah teoretis. ${ }^{6}$ Pound ingin mengubah hukum dari tataran teoretis (law in book) menjadi hukum dalam kenyataan (law in action). Oleh karena itu sebagai pendukung aliran pragmatic legal realism, Pound juga menyatakan bahwa

4 Ibid.

6 \footnotetext{
(jurisprudence) dapat dianggap sebagai ilmu pengetahuan (science) apabila menggunakan metode-metode ilmiah atau paling tidak didasarkan kepada metode ilmu-ilmu empiris seperti sosiologi atau psikologi. Oleh karena itu ilmu hukum sejatinya bersifat deskriptif. Metode ini antara lain digunakan oleh aliran Free Law, American Realism, Socialogical Jurisprudence, dan Scandinavian Realism. Lihat Jerzy Stelmach \& Bartos Brozek, Methods of Legal Reasoning, the Netherlands, Springer, 2006, hlm. 3. Lihat juga Marett Leiboff \& Mark Thomas, Legal Theories in Principle, Sydney: Thomson Lawbook Co, 2004, hlm. 212; Suri Ratnapala, Jurisprudence, Cambridge: Cambridge University Press, 2009, hlm. 207; Raymond Wacks, Understanding Jurisprudence: An Introduction to Legal Theory, Oxford University Press, Oxford, 2005, hlm. 199.

5 Lihat H. Lloyd, Introduction to Jurisprudence, New York/Washington, 1972, hlm. 366. Lihat juga Roscoe Pound,

Outlines of Lectures on Jurisprudence, Cambridge, 1943, hlm. 104.

Roscoe Pound, Contemporary Juristic Theory, Claremont CA: Pamona College, 1940, hlm. 66.

Aliran ini berbasis kepada metode penalaran hukum naturalistik yang menyatakan bahwa ilmu hukum

Hari Chand, Modern Jurisprudence, Petaling Jaya: International Law Book Services, 2005, hlm. 195.

Ibid., hlm. 36-37.
} 
hukum yang sebenarnya adalah hukum yang dijalankan. Hukum bukan hanya yang tertulis dalam undang-undang, melainkan apa yang dilakukan oleh aparat penyelenggara hukum dan atau siapa saja yang melaksanakan fungsi pelaksanaan hukum dengan konsep hukumnya, yaitu hukum dapat berperan sebagai sarana perubahan masyarakat (law as a tool of social engineering). ${ }^{7}$ Pemikiran Pound mulai dikenal, bahkan terkenal, di Indonesia setelah salah satu tokoh pemikir hukum Indonesia yang juga Guru Besar Fakultas Hukum Unpad, Mochtar Kusumaatmadja, memperkenalkan pemikirannya mengenai pembangunan hukum di Indonesia pada tahun 1970-an.

\section{Sketsa Biografis}

Nama lengkapnya adalah Nathan Roscoe Pound. Dilahirkan pada tanggal 27 Oktober 1870 di Lincoln, Nebraska, Amerika Serikat, dari pasangan Stephen Bosworth Pound dan Laura Pound. Stephen Pound sendiri adalah seorang hakim. Sebelum terjun ke dunia hukum, Pound adalah doktor botani lulusan Universitas Nebraska (1888) dan sempat memimpin sebuah survei botani di Nebraska yang kemudian menghasilkan temuan spesies jamur langka yang kemudian dikenal dengan "roscoupondia". Karya tulis Pound di bidang botani tetap dianggap penting dan relevan sampai saat ini. Pound juga meraih Master of Arts dari Universitas Nebraska (1889) dan kemudian melanjutkan kuliah hukum di Universitas Harvard (1889-1890). Pound dikenal sebagai figur pekerja keras yang selalu bekerja 16 jam setiap hari dan memiliki kekuatan memori yang sangat fenomenal serta diakui pula sebagai seorang intelektual yang sangat 'curious'.

Pada tahun 1901-1903, Pound diangkat sebagai anggota Komisi Banding padaMahkamah Agung Nebraska dan menghasilkan sekitar 102 pendapat hukum yang kerap dijadikan rujukan. Pound juga menduduki posisi sebagai anggota Komisi Unifikasi Hukum untuk Nebraska (1904-1907). Dia juga mengajar di beberapa fakultas hukum seperti Universitas Nebraska, Universitas Nothwestern, Universitas Chicago, dan Universitas Harvard. Pada tahun 1910, Pound diangkat sebagai Guru Besar Hukum di Universitas Harvard dan kemudian diangkat sebagai Dekan pada periode 1916-1936. Kepemimpinan Pound diakui sebagai masa keemasan Fakultas Hukum Harvard (Harvard Law School's golden age). Pound mendesain sistem pendidikan hukum Fakultas Hukum Harvard sedemikian rupa supaya kondusif dalam mengimplementasikan pemikiran hukumnya yang berbasis kepada aliran sociological jurisprudence. Pound dan para lulusan Fakultas Hukum Harvard aktif

7 Roscoe Pound, Contemporary Juristic Theory, Op.cit., hlm. 80. 
memberikan kontribusi untuk memperkuat program New Deal Presiden F.D. Roosevelt.

Pada tahun 1936, Pound pensiun sebagai Dekan dan kemudian diangkat sebagai salah satu dari the first Harvard roving professorship. Pada tahun 1938, dia diangkat sebagai Director of the National Conference of Judicial Councils. Pound dianugerahi medali oleh American Bar Association pada tahun 1940 atas jasa-jasanya dalam mengembangkan pemikiran hukum di Amerika. Pound pensiun dari Universitas Harvard pada tahun 1947, tapi ia tetap mengajar di berbagai fakultas hukum dan mempublikasikan berbagai karya tulisnya. Dia meninggal pada tanggal 1 Juli 1964 di Cambridge, Massachusetts. Pound mewariskan sekitar 1000 karya tulis di bidang hukum termasuk lima volume bukunya, "Jurisprudence" yang ditulis pada tahun 1959 dan sekaligus merupakan magnum opus-nya Pound.

\section{Teori Kepentingan}

Menurut Pound, hukum adalah kepentingan-kepentingan tertentu (certain interests), yang menurut masyarakat kepentingan tersebut harus dilindungi oleh hukum. Lebih lanjut, Pound menyatakan bahwa tidak semua kepentingan tersebut harus dilindungi oleh hukum. Ada sejumlah kepentingan sosial yang bisa dilindungi melalui agama, moral dan estetika, dan bentuk perlindungan lainnya. ${ }^{8}$ Sehubungan dengan fungsi hukum, ia menyatakan bahwa fungsi utamanya adalah untuk melindungi kepentingan, yaitu kepentingan umum, kepentingan sosial, dan kepentingan pribadi. $^{9}$ Perlindungan terhadap ketiga kepentingan tersebut harus dilakukan secara seimbang. Keseimbangan yang harmonis inilah yang merupakan hakikat dari keadilan. Atas dasar ini, secara garis besar Pound membuat tiga kategori kepentingan yaitu kepentingan individual (individual interests), kepentingan publik (public interests), dan kepentingan negara sebagai penjaga kepentingan masyarakat (interest of the state as a guardian of social interest).

Kepentingan individual yang oleh Pound kemudian disamakan dengan hukum perdata (private law) adalah tuntutan, permintaan, kehendak dan harapan yang terkait dengan kepentingan dan kehidupan pribadi. Dia membagi kepentingan individual ini menjadi tiga kelompok yaitu pertama, kepentingan pribadi (personality interests) misalnya kebebasan minat, kehormatan dan reputasi, perlindungan hak pribadi (privacy), dan kebebasan berkeyakinan dan berpendapat. Kedua, hubungan domestik (domestic relations) seperti perkawinan. Ketiga, kepentingan yang bersifat 
substansi (interests of substance) seperti kepemilikan aset (property), kebebasan untuk berserikat (freedom of association), keberlangsungan pekerjaan (continuity of employment). ${ }^{10}$

Kepentingan publik yang oleh Pound disamakan dengan hukum publik adalah tuntutan, permintaan, kehendak, dan harapan individu yang terkait dengan kehidupan politik. Oleh karena itu kepentingan publik akan memiliki karakteristik dan relasi dengan kepentingan negara. Sementara itu kepentingan sosial didefinisikan oleh Pound sebagai tuntutan, permintaan, kehendak, dan aspirasi masyarakat yang beradab yang ingin diwujudkan dalam kehidupan sosial mereka. Wujud dari kepentingan sosial antara lain jaminan keselamatan, jaminan kesehatan, keamanan dan ketertiban. ${ }^{11}$

Dalam rangka memformulasikan beragam kepentingan tersebut menjadi sebuah keseimbangan yang harmonis, Pound memperkenalkan konsep Social Engineering yang diakui oleh para pemikir hukum lainnya sebagai ide sentral dari keseluruhan pemikiran Pound mengenai hukum. Dengan konsep Social Engineering, Pound mengibaratkan seorang ahli hukum (lawyer) seperti seorang insinyur (engineer). Ketika seorang insinyur akan membangun sebuah jembatan misalnya, maka pertama-tama ia akan membuat perencanaan dan kemudian mengumpulkan material-material yang diperlukan. Selanjutnya sang insinyur akan membuat penyesuaian-penyesuaian dengan mempertimbangkan situasi faktual di lapangan. Seorang ahli hukum menurut Pound harus mampu menghasilkan hukum yang sesuai dengan kebutuhan dan kepentingan masyarakat. ${ }^{12}$

Dengan konsep Social Engineering, ahli hukum dan hakim harus meninggalkan sikapnya yang kaku (rigid) dalam memahami hukum dan harus mengakomodasi perubahan-perubahan yang terjadi di masyarakat sehingga hukum dapat menjembatani terciptanya kepuasan dalam pemenuhan kepentingan dan aspirasi masyarakat dan meminimalkan terjadinya friksi sosial. Dalam konteks inilah Pound kemudian mendefinisikan kepentingan (interests) sebagai tuntutan (claim), kebutuhan (wants), dan kehendak (desires) serta harapan (expectations) dari masyarakat. Dengan konsep Social Engineering seorang ahli hukum atau hakim harus mampu menyeimbangkan konflik dan benturan kepentingan di masyarakat menjadi sebuah keseimbangan dan harmony (a happy balance)..$^{13}$

10 Marrett Leiboff and Mark Thomas, Legal Theories in Principle, Op.cit., hlm. 214.

11 Ibid.

12 Suri Ratnapala, Jurisprudence,,Op.Cit., hlm. 208.

13 Roscoe Pound, Contemporary Juristic Theory, Op.Cit., hlm. 69. Lihat juga M.D.A.Freeman, Lloyd's Introduction to Jurisprudence, UK: Sweet \& Maxwell, 2007, hIm. 675. 
Dalam rangka menjembatani konflik kepentingan menjadi harmoni, Pound menyarankan agar kepentingan-kepentingan tersebut dikemas menjadi bentuk tertentu yang memiliki tingkat dan kualitas yang sama. Contoh, kebebasan pribadi adalah salah bentuk kepentingan individual dan keamanan negara adalah wujud dari kepentingan publik. Negara berkepentingan untuk menjaga keamanan negara dari segala bahaya yang mengancamnya. Oleh karena itu, dalam hal-hal tertentu negara akan membatasi kebebasan pribadi demi keamanan negara. Situasi ini akan menyebabkan seseorang merasa kebebasan pribadinya dibatasi dan hal ini akan menyebabkan terjadinya benturan kepentingan (clash of interests). Menghadapi situasi ini ahli hukum atau hakim harus mencari keseimbangan nilai dari masingmasing pihak dan kemudian harus menemukan dan memutuskan seberapa besar kebebasan pribadi yang akan diberikan kepada warganegara sehingga negara aman dan kebebasan pribadi tidak dibatasi secara tidak patut. ${ }^{14}$

Menurut Pound, benturan kepentingan itu harus diletakkan dalam satu bidang yang sama, yaitu kepentingan masyarakat. Dalam contoh di atas, kebebasan pribadi adalah bentuk dari kebebasan individual yang juga merupakan kepentingan sosial, karena masyarakat juga berkepentingan untuk memberikan kebebasan pribadi. Oleh karena itu, apabila kita menempatkan kepentingan individual dari sisi pandang masyarakat, maka ia akan menjadi sebuah kepentingan masyarakat pula. Negara berkepentingan untuk menjaga keamanan negaranya. Ini merupakan wujud dari kepentingan publik (public interests) dan masyarakat berkepentingan pula untuk menjaga keamanan negara. Dengan demikian, kepentingan publik menjadi kepentingan masyarakat (social interests) apabila di persepsi dari sisi masyarakat. Menurut Hari Chand, "Pound wants us to look at every interest from the point of view of the society. Thus, Pound says, we can balance them". ${ }^{15}$

\section{Social Engineering}

Social Engineering (rekayasa sosial) merupakan konsep sentral dan dominan dari keseluruhan bangunan pemikiran hukum Roscoe Pound. Hal ini merupakan konsekuensi logis dari akar pemikiran Pound yang berbasis kepada sosiologi. Pound menjadikan sosiologi sebagai fondasi utama dalam menciptakan teori hukumnya yang ide utamanya adalah untuk mentransfomasikan hukum dalam tataran ide menjadi hukum dalam tataran realitas (to bring the law in books into direct contact with the law in action). Hukum tidak boleh diisolasi dan terisolasi dari realitas sosial yang dinamis. ${ }^{16}$

\footnotetext{
14 Raymond Wacks, Understanding Jurisprudence: An Introduction to Legal Theory, Op.Cit., hlm. 200.

15 Hari Chand, Modern Jurisprudence, Op.cit., hlm. 199.

16 Marrett Leiboff and Mark Thomas, Legal Theories in Principle, Op.cit.,hlm. 212.
} 
Pemikiran hukum Pound yang digolongkan kepada aliran sociological jurisprudence dimaksudkan juga sebagai respons terhadap paham positivisme hukum dan juga metode-metode Common Law yang dominan pada permulaan sampai dengan akhir abad ke-20 yang dinilainya tidak responsif terhadap perubahan sosial dan tidak mampu mengakomodasi kebutuhan-kebutuhan masyarakat akibat dari booming ekonomi Amerika. ${ }^{17}$ Esensi aliran sociological jurisprudence dapat dipahami dengan mengetahui apa yang menjadi tantangan aliran tersebut. Tantangan utamanya adalah kekakuan hukum dalam bingkai positivisme yang menjadikan hukum terisolasi dari realitas sosial. Secara demikian, maka aliran sociological jurisprudence akan dipahami sebagai upaya untuk menjaga hukum agar tidak ter'kerangkeng' dengan pendekatan yang formalistik, mekanistik, dan analisis hukum 'rigid' yang gagal untuk mengakomodasi perubahan yang diperlukan untuk menjadikan hukum tetap relevan dengan kebutuhan masyarakat. Untuk itu, Pound kemudian mengusulkan adanya kerjasama yang erat (inter-connected actions) antara akademisi hukum, peradilan, dan profesi hukum untuk mencapai tujuan tersebut. Inilah yang oleh Pound disebut sebagai Social Engineering. ${ }^{18}$

Istilah "Social Engineering" digunakan oleh Pound ketika menjelaskan mengenai fungsi dan peran hukum dan ahli hukum (lawyers). Menurut Pound, ahli hukum itu harus berperan seperti seorang insinyur (engineer) ketika yang bersangkutan akan mendirikan sebuah bangunan, jembatan, dan sebagainya. Dalam hal ini seorang insinyur akan membuat dan menyiapkan sebuah perencanaan (planning) yang kemudian akan diikuti dengan pengumpulan material-material yang diperlukan. Selanjutnya sang insinyur akan membuat sejumlah penyesuaian antara material yang terkumpul dengan perencanaan yang dibuat agar sesuai dengan kebutuhan. Dalam konteks ini Pound kemudian menganalogikan seorang ahli hukum dengan seorang insinyur ketika yang bersangkutan akan membuat hukum. Ahli hukum harus memiliki perencanaan yang matang, mampu menginventarisasi kebutuhan-kebutuhan masyarakat dan selanjutnya ahli hukum tersebut harus mampu melakukan penyesuaian-penyesuaian dan keseimbangan dari berbagai kepentingan tersebut sehingga tercipta bangunan hukum yang kokoh dan fungsional. ${ }^{19}$

Konsep "Social Engineering" didesain sebagai upaya untuk menciptakan keseimbangan dan harmoni dari konflik kepentingan individual yang ada di masyarakat (conflict of interests of individuals). Dengan perkataan lain, konflik kepentingan adalah objek utama dari operasi konsep Social Engineering-nya Pound. 
Konsep ini didasarkan atas pemikiran bahwa hukum adalah sarana yang dapat digunakan untuk membentuk masyarakat dan mengatur perilaku manusia. Meminjam bahasa Mayneni, seorang pakar hukum dari India: "It is an attempt to control the human conduct through the help of law". ${ }^{20}$ Atas dasar ini maka Pound mengatakan, "Law is social engineering which means a balance between the competing interests in society. Like an engineer's formulae, laws represent experience, scientific formulations of experience and logical developments of the formulations, also inventive skill in conceiving new devices and formulating their requirements by means of a developed technique". ${ }^{21}$ Pound menamai konsep ini dengan "Theory of Social Engineering".

Dua kata yang digunakan dalam teori "Social Engineering" adalah pertama, kata "social" yang merujuk kepada kelompok individu yang membentuk suatu masyarakat dankedua, kata "engineering" yang berarti ilmu terapan yang digunakan oleh seorang insinyur untuk menghasilkan produk akhir yang diperlukan oleh masyarakat yang diperlukan untuk memenuhi kebutuhan masyarakat tersebut. Dengan mengkombinasikan kedua kata tersebut Pound berbicara mengenai fungsi dan peran seorang insinyur. Seorang insinyur akan menggunakan formula yang didasarkan pada eksperimen dan pengalaman yang berkelanjutan untuk menghasilkan suatu produk akhir dengan menggunakan suatu instrumen atau sarana (device). Selanjutnya, Pound menganalogikan pengalaman (experience) dengan hukum, instrumen dengan organ pemerintah, insinyur dengan hakim dan ahli hukum, dan produk akhir sebagai analogi kebutuhan manusia (the wants of human being), dan masyarakat dianalogikan dengan sebuah pabrik. Menurut Pound, sebagaimana halnya seorang insinyur, hakim dan ahli hukum harus menerapkan hukum di ruang pengadilan yang memungkinkan aspirasi masyarakat dapat dipenuhi dan dilaksanakan. Oleh karenanya Pound kemudian menyebut hukum sebagai a tool of social engineering.

Pemikiran Pound lahir sebagai respons ketika Amerika mengalami periode perubahan masyarakat yang sangat dahsyat, namun pada saat yang sama para ahli hukum justru sedang berkubang pada perilaku berpikir yang statis, menempatkan hukum sebagai bintang yang tak pernah bergerak (fixed star). Pound berpendapat bahwa dengan menganalogikan hukum sebagai sarana perubahan sosial maka ahli hukum dan hakim harus meninggalkan sikapnya yang kaku (rigid) dan sebaliknya harus menjadikan hukum agar dapat beradaptasi dan mengakomodasi perubahan sehingga para ahli hukum dan hakim dapat membantu masyarakat untuk mencapai

20 S.R. Mayneni, Jurisprudence (Legal Theory), $2^{\text {nd }}$ edition, Asia Law House, Hyderabad, 2007, hlm. 511.

21 Sebagaimana dikutip Mayneni, Ibid. 
kepuasan maksimum atas aspirasi dan kebutuhannya dengan menekan sesedikit mungkin adanya friksi dan konflik. ${ }^{22}$

Menganalogikan hakim dan ahli hukum dengan peran seorang insinyur sebenarnya tidak bisa dipahami secara sederhana bahwa Pound sedang melakukan mekanisasi fungsi hukum. Menempatkan hukum dengan pendekatan mekanik yang cenderung kaku dan anti sosial. Pound justru ingin menjadikan hukum sebagai medium dinamis yang mampu memfasilitasi adanya kohesi sosial dengan menggunakan berbagai macam cara (teknik) yang memungkinkan semua aspirasi masyarakat dapat terpenuhi dan terlaksana. Dalam hal ini Pound menerapkan pendekatan yang beraneka segi (multi-faceted) dan pendekatan bertingkat (multistaged) yang dia sebut sebagai teori kepentingan (theory of interest) untuk mencapai tujuan dari konsep Social Engineering. Untuk mencapai hal tersebut, Pound membuat pemetaan sebagai berikut: pertama, menemukan dan menetapkan apa yang menjadi kepentingan masyarakat (interest); kedua, menginventarisasi dan mengklasifikasi kepentingan tersebut; dan ketiga, apabila ada konflik kepentingan, maka dilakukan harmoni dan penyeimbangan. ${ }^{23} \mathrm{Hal}$ itu semua dilakukan dengan dan melalui hukum.

Jadi menurut Pound, tugas hakim, ahli hukum, dan legislator adalah melakukan "Social Engineering". Dengan melakukan identifikasi dan proteksi terhadap kepentingan masyarakat, maka hukum akan menjamin adanya kohesi sosial. Pound mendefinisikan kepentingan (interest) sebagai tuntutan dan kehendak yang manusia baik secara individu maupun kelompok mengusahakannya untuk memperolehnya. Kepentingan tersebut dilindungi secara hukum dengan memberikan kepadanya status sebagai hak hukum (legal right). Tujuan utama dari konsep Social Engineering adalah: "to construct as efficient a structure of society as possible which requires the satisfaction of wants with the minimum of friction and waste of resources. It means Law should work for balancing of competing interest within the society for the greatest benefit". ${ }^{24}$ Menurut Hari Chand, konsep Social Engineering bertujuan: "to enable the lawyer to think in terms of changing or moulding the law" ${ }^{25}$

\section{Harmonisasi dan Keseimbangan Kepentingan}

Salah satu pertanyaan kritis terkait dengan penerapan konsep "Social Engineering" dan "teori kepentingan" dari Roscoe Pound adalah bagaimana caranya untuk

22 Hari Chand, Modern Jurisprudence, Op. Cit.,hlm. 198

23 Marrett Leiboff and Mark Thomas, Legal Theories in Principle, Op. Cit., hlm. 213.

24 Raymond Wacks, Understanding Jurisprudence: An Introduction to Legal Theory, Op. Cit., hlm. 200.

25 Hari Chand, Modern Jurisprudence, Op. Cit., hlm. 198. 
mengharmonikan berbagai kepentingan yang ada di masyarakat yang potensial melahirkan konflik. Dalam hal ini, Pound menawarkan resep berupa transformasi beragam kepentingan tersebut kedalam satu bentuk yang memungkinkannya untuk menempatkan beragam kepentingan tersebut dalam level yang sama. Misalnya, kebebasan pribadi yang merupakan kepentingan individu dan juga keamanan negara keduanya diklasifikasikan sebagai kepentingan publik (public interest). Negara dapat membatasi kebebasan pribadi untuk kepentingan keamanan negara. Ketika hal ini terjadi, seorang individu merasa bahwa kebebasannya dibatasi. Konsekuensinya, terjadi benturan dua kepentingan, individu dan negara. Menurut Pound, ketika terjadi benturan kepentingan, maka hakim harus menyeimbangkan nilai dari masingmasing kepentingan tersebut dan kemudian memutuskan seberapa besar kebebasan yang harus diberikan kepada individu yang dapat menjamin keamanan negara dan kebebasan individu tidak terbatasi secara tidak layak. ${ }^{26}$

Meskipun demikian, dalam keadaan tertentu kebebasan pribadi yang dianggap sebagai kepentingan individual juga dapat digolongkan kedalam kepentingan masyarakat (social interest), karena masyarakat berkepentingan juga untuk memberikan kebebasan kepada individu-individu. Dalam konteks ini, apabila kepentingan individu dilihat dari sudut pandang masyarakat, maka kepentingan individu itu menjadi bagian dari kepentingan masyarakat. Negara berkepentingan untuk melindungi keamanan negara yang merupakan bentuk dari kepentingan publik. Masyarakat juga berkepentingan untuk menjaga keamanan negara. Dalam hal ini, kepentingan publik (negara) akan menjadi kepentingan masyarakat apabila dilihat dari sudut pandang kepentingan masyarakat. Dengan perkataan lain, Pound berpendapat bahwa untuk menciptakan harmoni dan keseimbangan beragam kepentingan tersebut harus diletakkan dari sudut pandang kepentingan masyarakat. ${ }^{27}$

Ada catatan penting terkait dengan harmonisasi dan penyeimbangan kepentingan ini yaitu mengenai parameter yang digunakan. Dalam hal ini Pound tidak memberikan parameter yang jelas. Tidak terlalu mudah untuk membandingkan kualitas satu kepentingan dengan kepentingan lainnya. Disini menyangkut persoalan penggunaan nilai (value) ketika menentukan suatu kepentingan lebih tinggi dari kepentingan lainnya. Apabila tidak ditetapkan suatu parameter untuk menentukan nilai dari masing-masing kepentingan tersebut, maka upaya harmonisasi dan penyeimbangan kepentingan akan dilakukan secara arbitrer.

26 Ibid, hlm. 199.

27 Ibid. 


\section{Jural Postulates}

Secara harfiah "Jural Postulates" kita terjemahkan menjadi postulat hukum. "Jural" berasal dari bahasa latin "iur" yang berarti hukum atau segala sesuatu yang berhubungan dengan hukum, atau bisa juga diartikan sebagai hak dan kewajiban. Sedangkan "postulate" adalah suatu asumsi yang dianggap benar dengan sendirinya tanpa perlu pembuktian. Dalam pemikiran Pound, "Jural Postulates" digunakan untuk menguji dan mengevaluasi ketika sebuah kepentingan (interest) harus diakui atau dilindungi oleh hukum. "Jural Postulates" akan digunakan untuk menentukan nilai dari kepentingan tersebut.

Menurut Pound: "Jural postulates are generalised principles of the law at a given place and time, they are not closed, and will continue to develop and change as the new claims are brought into law". 28 "Jural postulates" ditemukan atau berada dalam hukum itu sendiri dan digunakan sebagai metode penalaran (method of reasoning) untuk menguji sebuah klaim kepentingan baru. Pound mengajukan beberapa "Jural Postulates" antara lain sebagai berikut:

1. Dalam suatu masyarakat yang beradab (civilised society) seseorang harus memiliki asumsi bahwa pihak lain tidak akan secara sengaja melakukan penyerangan (aggression) kepada yang bersangkutan.

2. Dalam suatu masyarakat yang beradab seseorang harus memiliki asumsi bahwa yang bersangkutan, untuk sesuatu yang menguntungkan, dapat melakukan kontrol terhadap apa yang mereka temukan, atau apa yang dihasilkan oleh karyawannya, atau apa yang didapatkannya sesuai dengan tatanan sosial dan ekonomi yang berlaku.

3. Dalam suatu masyarakat yang beradab seseorang memiliki asumsi bahwa yang terlibat suatu tindakan, yang bersangkutan akan bertindak secara hati-hati dan tidak akan melakukan tindakan yang mendatangkan risiko bagi orang lain.

4. Dalam suatu masyarakat yang beradab seseorang harus memiliki asumsi bahwa pihak lain yang mempertahankan sesuatu atau mempekerjakan agen-agennya, perbuatan tersebut tidak berbahaya ketika digunakan oleh yang bersangkutan akan tetapi berbahaya ketika digunakan ditempat lain, namun perbuatan tersebut memiliki kecenderungan untuk digunakan secara lintas batas, maka perbuatan tersebut harus dilakukan secara benar sebagaimana digunakan oleh yang bersangkutan.

Namun, Pound mengakui bahwa "Jural Postulates" ini tidak bersifat absolut, ia memiliki nilai yang relatif. "Jural Postulates" adalah suatu standar ideal yang senantiasa mengikuti perubahan yang terjadi di masyarakat. Jadi, "Jural Postulates" 
menurut Pound adalah semacam pedoman untuk menciptakan masyarakat yang baik dan beradab dan juga untuk melakukan sintesis antara cita dan realita, dan juga semacam kekuatan dan akuntabilitas sosial dalam suatu masyarakat.

\section{Kontribusi}

Sebagaimana halnya kontribusi aliran sociological jurisprudence pada umumnya, kontribusi pemikiran Pound juga terletak pada kajiannya mengenai interaksi antara hukum dan lingkungan sosialnya (its social milieu). Pound menekankan pada fungsi hukum yang dinamis dalam masyarakat. Dia sangat konsisten berpendirian bahwa nilai-nilai sosial terekspresikan didalam hukum itu sendiri. ${ }^{29}$ Pemikiran Pound ini dapat dikatakan merupakan sintesis antara positivisme hukum dan ajaran hukum alam. Meskipun demikian, keinginan Pound untuk 'menguliti' kelemahan positivisme hukum yang pendekatannya bersifat 'rigid' dan sempit, mekanistik, dan kering (infertile), namun teori Social Engineering-nya justru menjadi hambatan atas kritik

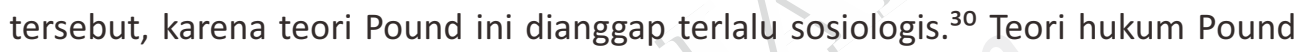
dapat membantu untuk memahami evolusi hukum secara benar dan tepat. Penekanan Pound pada kepentingan masyarakat dalam melakukan harmonisasi kepentingan merupakan hal yang sangat penting bagi ahli hukum dalam memahami suatu sistem hukum. Diatas itu semua, kontribusi terbesar Pound adalah kemampuannya untuk mengidentifikasi persoalan-persoalan hukum dan masyarakat secara tepat dan bukan pada respons dan jawaban yang disediakan untuk itu. Dengan bahasa yang pas Hari Chand mengatakan: "..his most important legacy was in the question he posed rather than the answer he provided". ${ }^{31}$

\section{Kritik}

Ada sejumlah kritik dialamatkan kepada Pound dengan teori "Social Engineering"nya. Beberapa diantaranya adalah:

1. Teori "Social Engineering" tidak bisa diaplikasikan kepada hukum, karena seorang insinyur akan membuat perencanaan untuk sesuatu yang bersifat tetap dan mekanistik. Hal ini tidak bisa diterapkan dalam dunia hukum yang aplikasinya di dalam masyarakat yang sangat dinamis dan tunduk kepada berbagai perubahan. Namun, kritik ini sebetulnya tidak menangkap esensi dari teori "Social Engineering-nya" Pound. Pound tidak menginginkan sebuah masyarakat yang kaku dan mekanistik. Justru yang diinginkan Pound adalah masyarakat yang dinamis yang didesain secara tepat dengan mempertimbangkan kebutuhan dan

\footnotetext{
29 Ibid.

20 lbid.

31 Ibid., hlm. 202.
} 
aspirasi anggota masyarakat yang bersangkutan. Pound tidak bermaksud menyamakan secara kaku tugas dan fungsi seorang insinyur dengan hakim dan ahlihukum.

2. Fondasi filosofis pemikiran hukum Pound adalah pragmatisme. Pound mendefinisikan hukum dilihat dari fungsinya. Oleh karena itu, teori hukum Pound sebetulnya kurang sempurna, karena Pound menciptakan suatu tertib hukum tanpa melibatkan norma hukum. Meskipun Pound kerapkali berbicara mengenai norma absolut dari keadilan, tapi dalam kenyataannya Pound tidak mengakui norma tersebut atau dia mengacaukannya dengan norma sosial atau norma budaya.

3. Kritik juga dialamatkan kepada konsep kepentingan. Apakah kepentingan (interest) itu, misalnya kepentingan individual, fakta atau nilai? Apakah kita harus menerimanya sebagai suatu kepentingan inidividual apapun bentuknya atau kita harus melakukan penilaian sebelum menerimanya sebagai suatu bentuk kepentingan? Misalnya, seorang pencopet menginginkan jam tangan atau handphone yang kita miliki. Apakah kita harus mengakuinya sebagai sebuah kepentingan hukum yang bersangkutan yang harus dilindungi?

4. Konsep harmonisasi konflik kepentingan juga melahirkan sejumlah problem. Misalnya, apakah kepentingan buruh dan pemilik modal dapat dikompromikan atau direkonsiliasikan? Adalah sesuatu yang sulit untuk melakukan harmonisasi untuk kepentingan yang secara faktual tidak mungkin direkonsiliasikan (irreconcilable). Misalnya, kepentingan kelompok mayoritas versus minoritas.

5. Memberikan label kepada pemikiran Pound sebagai salah satu bentuk aliran sociological jurisprudence adalah kesimpulan yang keliru dan menyesatkan (misleading). Pemikiran Pound lebih tepat digolongkan sebagai "functional jurisprudence", karena pemikiran Pound terutama berkaitan dengan pengaruh hukum terhadap masyarakat yang menempatkan hukum sebagai faktor dominan daripada determinasi sosial dari hukum.

6. Konsep "Social Engineering" dianggap sebagai "jurisprudence of despair", karena konsep tersebut cenderung mengorbankan keadilan sosial demi efisiensi.

Atip Latipulhayat 